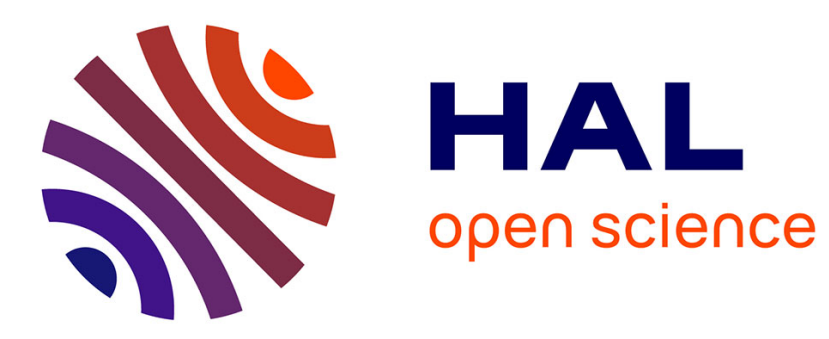

\title{
Application of the convolution theorem for the modeling of saturated induction motors
}

\author{
A. Ghoggal, Salah Eddine Zouzou, Hubert Razik, M. Sahraoui, A. \\ Hadri-Hamida
}

\section{- To cite this version:}

A. Ghoggal, Salah Eddine Zouzou, Hubert Razik, M. Sahraoui, A. Hadri-Hamida. Application of the convolution theorem for the modeling of saturated induction motors. 36th IEEE IECON, Nov 2010, Glendale, United States. pp.766-771, 10.1109/IECON.2010.5675228 . hal-00564329

\section{HAL Id: hal-00564329 \\ https://hal.science/hal-00564329}

Submitted on 8 Feb 2011

HAL is a multi-disciplinary open access archive for the deposit and dissemination of scientific research documents, whether they are published or not. The documents may come from teaching and research institutions in France or abroad, or from public or private research centers.
L'archive ouverte pluridisciplinaire HAL, est destinée au dépôt et à la diffusion de documents scientifiques de niveau recherche, publiés ou non, émanant des établissements d'enseignement et de recherche français ou étrangers, des laboratoires publics ou privés. 


\title{
Application of the Convolution Theorem for the Modeling of Saturated Induction Motors
}

\author{
A. Ghoggal ${ }^{1} *$, S.E. Zouzou ${ }^{1}$, H. Razik ${ }^{2}$, M. Sahraoui ${ }^{1}$, A. Hadri-Hamida ${ }^{3}$. \\ ${ }^{1}$ Laboratoire de génie électrique de Biskra (LGEB), Département d'électrotechnique, \\ Université Mohamed Khider, BP 145, 07000-Biskra, Algeria. \\ ${ }^{2}$ Université Lyon 1, Lyon, F-69622, France; CNRS, UMR5005, Laboratoire AMPERE, Villeurbanne, F-69622, France. \\ ${ }^{3}$ Laboratoire d'électrotechnique de Constantine (LEC). Université Mentouri, 25000-Constantine, Algeria. \\ *ghoetudes@yahoo.fr
}

\begin{abstract}
This paper proposes a new method for inductance calculation of induction motors (IM) based on the convolution theorem. The integral form leading to the inductance expressions is derived from the 2D modified winding function approach (2DMWFA). As first application, a model allowing teeth saturation to be taken into account by the corresponding air-gap permeance variation is proposed. The work points out that appropriate arrangements make it possible to use convolution theorem in favor of integral calculation leading to IM inductances. It is shown that the implication of the convolution concept in such a task reduces strongly the calculation process. Moreover, this method proves to be faster than integrations based on conventional methods. Simulation and experimental results confirm the performance and utility of the proposed technique.
\end{abstract}

Index Terms - Induction motor, 2D-MWFA, MCCM, slot skewing, saturation, convolution, FFT.

\section{INTRODUCTION}

Among the undesirable effects of magnetic saturation in IM is the reduction of the fundamental torque with rise of synchronous, asynchronous and parasitic torques [1]. However, whether in machine corps or teeth, reduction of the magnetic permeability of iron paths is the immediate result of saturation. This gives rise primordially to a third harmonic, but also to a series of odd harmonics in the magnetic field distribution. As reported by Stavrou et al. in [2], the set of frequency components arising from the asymmetries caused by the slotting, saturation and eccentricity can be described by

$$
f_{R S H+e c c+s a t}=\left(\frac{\left(k \cdot N_{b} \pm n_{d}\right)}{p} \cdot(1-s) \pm 2 . n_{s a t} \pm v\right) \cdot f_{s}
$$

where $f_{s}$ is the line frequency, $N_{b}$ the number of rotor bars, $p$ the pole pair number, $s$ the slip in per unit, $k$ is any positive integer and $n_{d}$ is the eccentricity order. $n_{d}=0$ in case of pure static eccentricity and $n_{d}=1,2, \ldots$ in presence of dynamic eccentricity component. $n_{\text {sat }}$ and $v$ are the saturation integer and the order of the time harmonics respectively $\left(n_{s a t}=1,2 \ldots, v\right.$ $=1,2, \ldots)$. The rotor slot harmonics (RSHs) correspond to $n_{\text {sat }}=0, n_{d}=0$ and $v=1$ while the particular case of $k=1$ gives the principal slot harmonics (PSHs). Despite many of its proprieties, saturation modeling has deserved a particular interest since eighties.

In [3], the saturation effect was accounted at the level of the magnetizing branch and leakage path, while [4] and [5] discussed the spatial dependency of saturation. As the air-gap flux and stator voltages contain the predominant third and higher frequency slot harmonics, Moreira et al. in [6] described a function between the third harmonic stator voltage and air-gap voltage for use in determining the fundamental of air-gap flux-linkage. Still in d,q axis, Levis in [7] introduced the concept of generalized flux and generalized inductances being the origin of various models of saturated smooth air-gap machines. Bispo et al. in [8] take account of the saturation by means of the magnetic harmonic functions obtained experimentally through the measure of the stator voltages and currents of the unloaded machine. A model proved to be adequate for diagnosis purposes was presented by Nandi in [1] where he discusses the influence of saturation on the spectral contents of the line current. Afterwards, for obtaining the airgap flux position, Ojaghi et al. in [9] were based on the fact that the peak value of the air-gap flux density is within the arc of a rotor mesh which has the most flux-linkage.

It should be noted that if the model topology is the first concern for the software designers, the data processing is another one. In the last decades, digital signal processing (DSP) is recognized as an important technologic component emerging in the field of electrical engineering. The knowledge of the basic theoretical concepts involved in the perfection of many signal processing systems may be of great interest in diverse purposes. Convolution operation is among the most involved basic techniques. Joined to the fast Fourier transform (FFT), convolution constitutes one of the powerful tools used in DSP and proves to be helpful for various tasks [10]. This work demonstrates that appropriate arrangements make it possible to perform a fast and easy inductance calculation of IM using the convolution theorem. As first application, the modeling of saturated IM taking into account the slot skewing and the multiple coupled circuit model (MCCM) is presented.

\section{INDUCTANCE CALCULATION USING CONVOLUTION CONCEPT}

Thanks to the 2D-MWFA, IM inductances can be evaluated using the known spatial winding and turn functions of the motor windings [11]. Then, one can predict IM transient and steady state behaviors by considering the radial and axial nonuniformities [12]. Although in case of air-gap eccentricity all inductances may be rotor position functions, rotor-stator mutual inductance remains the case of interest since it expresses mostly the magnetic interaction between the two armatures. In start, the method can be explained through the calculation of the mutual inductance $L_{A r j}$ between the first stator phase A and the $j^{\text {th }}$ rotor loop $r_{j}$ in case of unsaturated 
IM with unskewed rotor bars. So

$$
L_{A r_{j}}\left(\theta_{r}\right)=\frac{r_{0} \cdot \mu_{0} l}{g_{0}} \int_{0}^{2 \pi} N_{A}(\varphi) \cdot n_{r_{j}}\left(\varphi, \theta_{r}\right) \cdot d \varphi
$$

$\mu_{0}$ is the permeability in vacuum, $g_{0}$ the air-gap length in symmetrical condition, $\theta_{r}$ is the rotor angle with respect to a stator reference, $\varphi$ a particular angular position along the stator inner surface, $l$ the main rotor length, $r_{0}$ the average air-gap radius and $N_{A}$ and $n_{r j}$ are the winding function of stator phase $\mathrm{A}$ and turn function of rotor loop $r_{j}$ respectively. Taking $x=\varphi . r_{0}$ and $x_{r}=\theta_{r} . r_{0}$ for a plane representation yields [13]

$$
L_{A r_{j}}\left(x_{r}\right)=\frac{\mu_{0} l}{g_{0}} \int_{0}^{2 \pi \cdot r_{0}} N_{A}(x) \cdot n_{r_{j}}\left(x, x_{r}\right) \cdot d x .
$$

As described in [13], the inductance will depend on an implicit definition of the common surface areas $S_{D_{i j}}$ resulting from the crossing of $r_{j}$ under the field of the stator coils $A_{i}$ (Fig.1). Thus

$$
L_{A . r_{j}}\left(x_{r}\right)=\frac{\mu_{0}}{g_{0}} \cdot\left(\left(\sum_{i=1}^{v} w_{A_{i}} \cdot S_{D_{i j}\left(x_{r}\right)}\right)-\left\langle n_{A}\right\rangle \cdot\left\langle n_{r_{j}}\right\rangle\right),
$$

with

$$
S_{D_{i j}\left(x_{r}\right)}=\left\{\begin{array}{ll}
l .\left(x_{2 j}-x_{1 i}\right) & 0<\left(x_{2 j}-x_{1 i}\right)<\lambda_{r} . r_{0} \\
l . \lambda_{r} \cdot r_{0} & \lambda_{r} \cdot r_{0}<\left(x_{2 j}-x_{1 i}\right) \\
l .\left\{\lambda_{r} \cdot r_{0}-\left(x_{2 j}-x_{2 i}\right)\right\} & 0<\left(x_{2 j}-x_{2 i}\right)<\lambda_{r} . r_{0} \\
0 & \text { Otherwise }
\end{array} .\right.
$$

$v$ is the number of coils per stator phase, $w_{A i}$ is the number of turns of coil $A_{i}, \lambda_{r}$ is the rotor slot pitch while $\left(x_{1 i}, x_{2 i}\right)$ and $\left(x_{1 j}, x_{2 j}\right)$ are the sides coordinates of coil $A_{i}$ and loop $r_{j}$ respectively. Note that the rotor loop sides depend on $x_{r}$ because of the rotor relative displacement. Often we need the first derivative of the inductance so as to calculate the electromagnetic torque [12], [13]. From (4) derives

$$
\frac{d L_{A, r_{j}}\left(\theta_{r}\right)}{d \theta_{r}}=r_{0} \cdot \frac{d L_{A . r_{j}}\left(x_{r}\right)}{d x_{r}}=\frac{r_{0} \cdot \mu_{0}}{g_{0}} \sum_{i=1}^{v} w_{A_{i}} \frac{d S_{D_{i j}\left(x_{r}\right)}}{d x_{r}} .
$$

While $n_{A i}$ and consequently $N_{A}$ depend from $x, n_{r j}$ depends from $x$ and $x_{r}$. Following Fig. 1, it is possible to see that, if we substitute the linear displacements $\left(x_{r}, x\right)$ by the time variables $(t, \tau)$, two similarities arise; one between the rotor loop turn function and a shifted step function $a(t-\tau)$, and the other between the inductance and a step response of a system whose impulse response is $N_{A}$. This is most evident when considering in (3) a dummy variable $\xi=\left(x_{r}-x\right)$ [10]. That leads to

$$
L_{A r_{j}}\left(x_{r}\right)=\frac{\mu_{0} l}{g_{0}} \int_{0}^{2 \pi \cdot r_{0}} N_{A}(x) \cdot n_{r_{j}}\left(x_{r}-x\right) \cdot d x
$$

where

$$
n_{r_{j}}\left(x_{r}-x\right)=n_{r_{j}}(\xi)= \begin{cases}1 & (1-j) \cdot \lambda_{r} \cdot r_{0}>\xi>-\lambda_{r} \cdot r_{0} \\ 0 & \text { Otherwise }\end{cases}
$$

Knowing that $L_{A r j}$ is periodic and $x_{r}$ is time function, it is possible to observe now that the form and mathematical aspect of (7) can be described by the following convolution product

$$
\begin{aligned}
& L_{A r_{j}}\left(x_{r}\right)=\frac{\mu_{0} l l}{g_{0}}\left\{N_{A}\left(x_{r}\right) * n_{r_{j}}\left(x_{r}\right)\right\}
\end{aligned}
$$

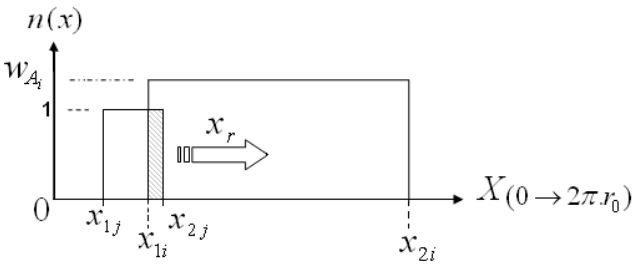

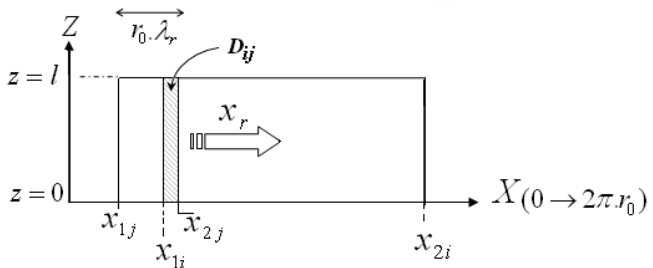

Fig.1. Stator coil and rotor loop turn functions (top). Crossing of the $j^{\text {th }}$ rotor loop under the field of the $i^{t h}$ coil of stator winding A in a plane representation (bottom).

As it appears, (9) may lead to some ambiguity as for the definition of $N_{A}$. This is because $N_{A}$ should depend only from $x$. Therefore, one must recall that only the integral forms like (3) could express clearly the known physical meanings of the turn and winding functions.

Based on the convolution theorem, the FFT of $N_{A} * n_{r j}$ is the same as multiplying the FFT of $N_{A}$ and that of $n_{r j}$ [14]. So

$N_{A} * n_{r_{j}}=F^{-1}\left\{F\left(N_{A}\right) \cdot F\left(n_{r_{j}}\right)\right\}$

$F$ denotes the FFT operator. For this basic case, the use of (9) by means of (10) offers a rapid calculation of the inductances, but not really valuable compared to (4). However, the usefulness of the convolution theorem becomes very obvious when the integral proves to be difficult or we won't even be able to evaluate it in a simple analytical formula. As example, if we choose to model the air-gap eccentricity or/and the saturation taking into account the skew effect, the proposed method turn out to be very helpful.

\section{MODELING OF SATURATED IM}

\section{A. The inverse of air-gap function}

Since in most practical machines, most of the saturation occurs at the stator and rotor teeth, only teeth saturation will be considered here. As reported and described in [5], we assume a pseudo air-gap length variation while the inverse of air-gap function is defined in dealing with multiplication of functions instead of division in the inductance expression. So

$g^{-1}\left(x, x_{f}\right)=K_{e}+K_{m} \cdot \cos \left(2 \cdot\left(p \cdot x-x_{f}\right) / r_{0}\right)$

The saturation constants are given by

$$
K_{m}=\frac{2 \cdot\left(K_{s}-1\right)}{3 \cdot K_{s}} g_{0}^{-1},
$$


$K_{e}=g_{0}{ }^{-1}-K_{m}=\frac{K_{s}+2}{3 \cdot K_{s}} \cdot g_{0}{ }^{-1}$

and

$\left\langle g^{-1}\right\rangle=K_{e}$

$K_{s}$ is the saturation factor while $\theta_{f}=x_{f} / r_{0}$ is the air-gap field position with respect to a chosen reference axis.

\section{B. Stator-rotor mutual inductances}

According to the 2D-MWFA, $L_{A r j}$ results from a double integration through a surface region $S=2 \pi \cdot r_{0} . l$ between the stator inner surface and the rotor outer surface so as [13]

$$
\begin{aligned}
& L_{A . r_{j}}\left(x_{r}, x_{f}\right)= \\
& \quad \mu_{0} \cdot \iint_{S} N_{A}\left(x, x_{f}\right) \cdot n_{r_{j}}\left(x, z, x_{r}\right) \cdot g^{-1}\left(x, x_{f}\right) \cdot d z \cdot d x
\end{aligned}
$$

When considering the skew angle of the rotor bars $\gamma$ yields

$$
L_{A . r_{j}}\left(x_{r}, x_{f}\right)=\mu_{0} \cdot \int_{x_{1 j}}^{x_{2 j}} \int_{z_{1 j}\left(x, x_{r}\right)}^{z_{2 j}\left(x, x_{r}\right)} N_{A}\left(x, x_{f}\right) \cdot 1 \cdot g^{-1}\left(x, x_{f}\right) \cdot d z \cdot d x
$$

with $x_{2 j}=x_{r}+\left(j \cdot \lambda_{r}+\gamma\right) \cdot r_{0}, x_{1 j}=x_{r}+(j-1) \cdot \lambda_{r} \cdot r_{0}$,

$$
\begin{aligned}
& z_{l j}\left(x, x_{r}\right)=\left\{\begin{array}{ll}
0, & x_{l j} \leq x \leq\left(x_{l j}+r_{0} \cdot \lambda_{r}\right) \\
\frac{l}{r_{0} \gamma}\left(x-x_{r}-j \lambda_{r} \cdot r_{0}\right), & \left(x_{l j}+r_{0} \cdot \lambda_{r}\right) \leq x \leq x_{2 j}
\end{array},\right. \\
& z_{2 j}\left(x, x_{r}\right)= \begin{cases}\frac{l}{r_{0} \gamma}\left(x-x_{r}-(j-1) \lambda_{r} \cdot r_{0}\right), & x_{l j} \leq x \leq\left(x_{l j}+r_{0} \cdot \gamma\right) \\
l, & \left(x_{l j}+r_{0} \cdot \gamma\right) \leq x \leq x_{2 j}\end{cases}
\end{aligned}
$$

and

$$
N_{A}\left(x, x_{f}\right)=n_{A}(x)-\frac{\left\langle g^{-1} \cdot n_{A}\right\rangle}{\left\langle g^{-1}\right\rangle} .
$$

Note that $n_{A}$ is obtained taking into account the linear rise of the magnetomotive force (MMF) across the slots [12]. Introducing $\xi=\left(x_{r}-x\right)$, the equation set (17) and (18) become

$$
\begin{aligned}
& z_{1 j}(\xi)=\left\{\begin{array}{lr}
0, & (1-j) \lambda_{r} . r_{0} \geq \xi \geq-j \lambda_{r} \cdot r_{0} \\
\frac{-l}{r_{0} \gamma}\left(\xi+j \lambda_{r} . r_{0}\right), & -j \lambda_{r} . r_{0} \geq \xi \geq-\left(j . \lambda_{r}+\gamma\right) \cdot r_{0}
\end{array}\right. \\
& z_{2 j}(\xi)= \\
& \left\{\begin{array}{lr}
\frac{-l}{r_{0} \gamma}\left\{\xi+(j-1) \lambda_{r} . r_{0}\right\}, & (1-j) \lambda_{r} \cdot r_{0} \geq \xi \geq\left\{(1-j) \lambda_{r}-\gamma\right\} . r_{0} \\
l, & \left\{(1-j) \lambda_{r}-\gamma\right\} . r_{0} \geq \xi \geq-\left(j \cdot \lambda_{r}+\gamma\right) \cdot r_{0}
\end{array}\right.
\end{aligned}
$$

In case of axial air-gap uniformity, (16) can be written as

$$
\begin{aligned}
& L_{A \cdot r_{j}}\left(x_{r}, x_{f}\right)= \\
& \mu_{0} \cdot \int_{0}^{2 \pi \cdot r_{0}} \underbrace{N_{A}(x) \cdot g^{-1}\left(x, x_{f}\right)}_{f_{x f}(x)} \cdot \underbrace{\left\{z_{2 j}\left(x_{r}-x\right)-z_{1 j}\left(x_{r}-x\right)\right\}}_{h\left(x_{r}-x\right)} \cdot d x
\end{aligned}
$$

Now, for any position of the air-gap field $x_{f}$, defining functions $f_{x_{f}}$ and $h$ as in (22), allows mutual inductance to be written as

$$
L_{A . r_{j}}\left(x_{r}, x_{f}\right)=\mu_{0} . f_{x_{f}}\left(x_{r}\right) * h\left(x_{r}\right)
$$

From (20) and (21), a definition of $h$ holds

$$
\begin{aligned}
& h(\xi)= \\
& \begin{cases}\frac{-l}{r_{0} \gamma}\left\{\xi+(j-1) \lambda_{r} \cdot r_{0}\right\}, & (1-j) \lambda_{r} \cdot r_{0} \geq \xi \geq\left\{(1-j) \lambda_{r}-\gamma\right\} \cdot r_{0} \\
l, & \left\{(1-j) \lambda_{r}-\gamma\right\} \cdot r_{0} \geq \xi \geq-j \lambda_{r} \cdot r_{0} \\
l \cdot\left(1+\frac{1}{r_{0} \gamma}\left(\xi+j \lambda_{r} \cdot r_{0}\right)\right), & -j \lambda_{r} \cdot r_{0} \geq \xi \geq-\left(j \lambda_{r}+\gamma\right) \cdot r_{0} \\
0, & \text { Otherwise }\end{cases}
\end{aligned}
$$

In order to achieve the numerical convolution, a discrete form of (23) results from division of an interval of size 2. $\pi . r_{0}$ into $m$ sampled values at equal intervals. Thus, the vector corresponding to the inductance values with respect to the rotor position is

$\left(L_{A . r_{j}}\right)_{m}=\Delta \cdot \mu_{0} \cdot f_{x_{f}} * h$

with $\Delta=2 \pi . r_{0} / m$. If we take both $f_{x_{f}}$ and $h m \times 1$ vectors, $L_{A . r_{j}}$ will be $(2 . m-1) \times 1$ vector elements. Since we speak about periodic sequences, only the $m$ appropriate values will be considered. Thanks to the convolution theorem, FFT provides fast and efficient calculation of inductances. Comparing this method and classical numerical integration illustrates a crucial distinction. If we take $m$ sampled values along the air-gap periphery, for a fixed value of $x_{f}$ and a chosen rotor position, classical numerical integration of (22) or (25) requires $m$ operations. Therefore, we need at least $\mathrm{m}^{2}$ operations in order to sweep one cycle revolution of the rotor $\left(2 . \pi . r_{0}\right)$. However, with the convolution theorem, the cost is only around $m \cdot \log (m)$ operations [10],[14]. Besides, it should be noted that the complexity of the air-gap function expression and its inverse is not a concern now. Once functions depending from $x$ and $\left(x_{r}-x\right)$ (called here $f$ and $h$ ) are adequately chosen, often the integrals are efficiently solved thanks to numerical convolution and FFT based algorithm.

\section{Stator inductances}

Practically, since stator magnetizing inductances does not vary with respect to $x_{r}$, there is no need to use convolution or to search analytical expressions of stator magnetizing inductances [12]. Accordingly, for any value of $x_{f}$, the stator inductances can be calculated only once using a simple numerical technique.

\section{Rotor inductances}

As in [12] and [13], rotor magnetizing and mutual inductances are computed using the developed forms

$$
L_{m r_{j}}\left(x_{r}, x_{f}\right)=2 \pi r_{0} l \mu_{0} \cdot\left(\left\langle g^{-1} . n_{r_{j}}\right\rangle-\frac{\left\langle g^{-1} \cdot n_{r_{j}}\right\rangle^{2}}{\left\langle g^{-1}\right\rangle}\right),
$$




$$
L_{r_{j} r_{k}}\left(x_{r}, x_{f}\right)=2 \pi r_{0} l \mu_{0}\left(-\frac{\left\langle g^{-1} \cdot n_{r_{j}}\right\rangle \cdot\left\langle g^{-1} \cdot n_{r_{k}}\right\rangle}{\left\langle g^{-1}\right\rangle}\right)
$$

and

$$
\left\langle g^{-1} \cdot n_{r_{j}}\right\rangle=\frac{1}{2 \pi r_{0} l} \int_{0}^{2 \pi \cdot r_{0}} \underbrace{g^{-1}\left(x, x_{f}\right)}_{f_{x_{j}}(x)} . \underbrace{\left\{z_{2 j}\left(x_{r}-x\right)-z_{1 j}\left(x_{r}-x\right)\right.}_{h\left(x_{r}-x\right)}\} d x .
$$

The inductances are calculated using (26), (27) and (28). $f_{x f}$ is chosen as indicated in (28) while $h$ keeps the same definition as in (22) and (24).

The described technique was applied to a 2-pole IM, 3phase stator winding with $2 / 3$ pitch. The motor has 28 skewed rotor bars and 36 stator slots [16]. Fig. 2 depicts the calculated stator-rotor mutual inductance and rotor loop magnetizing inductance as function of the rotor and air-gap field positions.
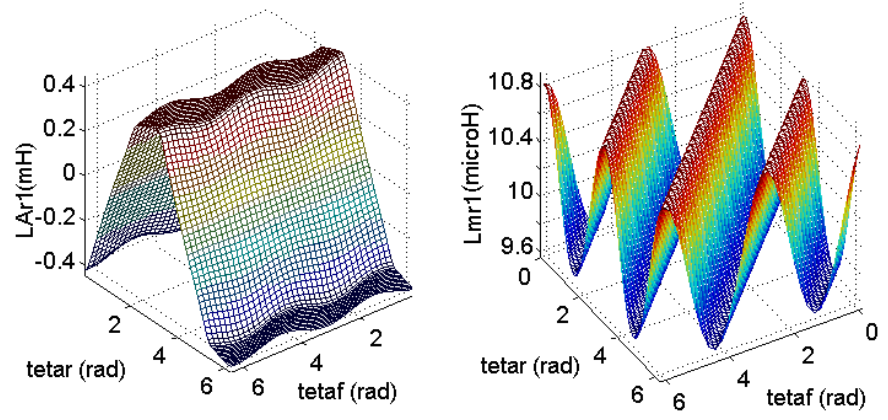

Fig.2. Mutual inductance $L_{A r l}$ between the first rotor loop and stator phase A (left) and rotor loop self inductance $L_{m r l}$ (right) in saturation conditions. $K_{s}=1.1$.
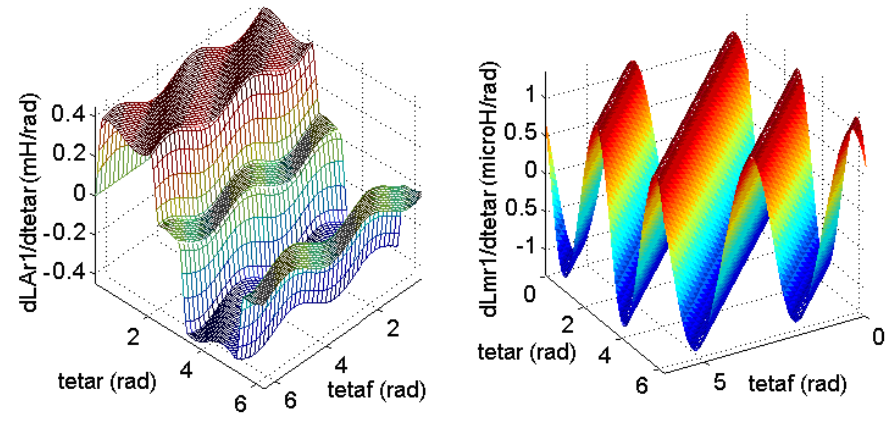

Fig.3. Derivative of the mutual inductance $L_{A r l}$ with respect to the rotor position (left) and that of rotor loop self inductance $L_{m r l}$ (right) in saturation conditions $K_{s}=1.1$.
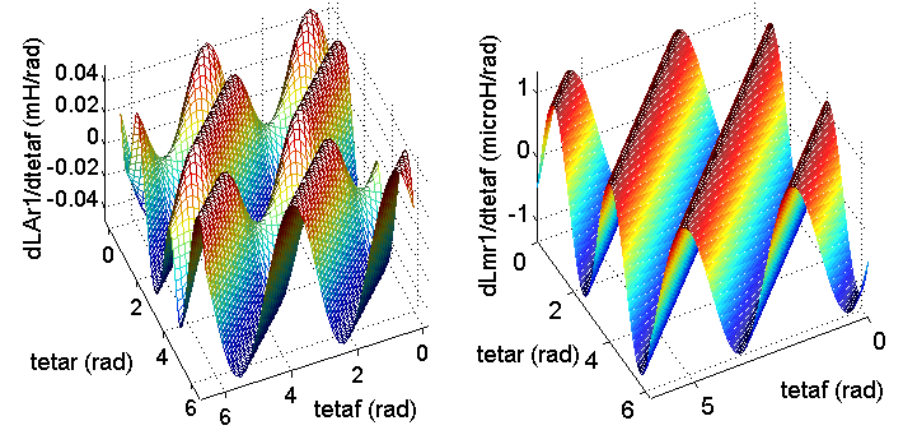

Fig.4. Derivative of the mutual inductance $L_{A r I}$ with respect to the air-gap field position $\theta_{f}$ (left) and that of rotor loop self inductance $L_{m r l}$ (right) in saturation conditions of $K_{s}=1.1$.
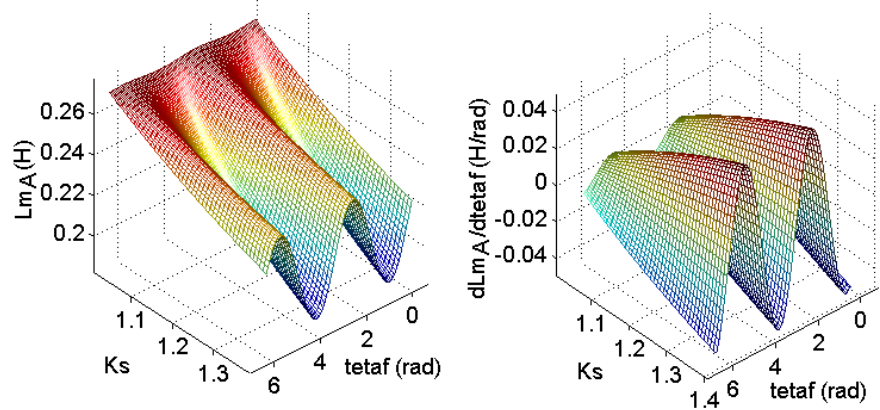

Fig.5. Magnetizing inductance of stator phase A as function of $\theta_{f}$ and $K_{s}$ (left) and its derivative with respect to $\theta_{f}$ (right).

The added part of the permeance function due to the saturation can be seen to affect the shape of the inductances and their derivatives (Fig. 3 and Fig. 4). On the other sides, this effect is noticeable at the level of the stator magnetizing inductance and its derivative with respect to $\theta_{f}$ as Fig. 5 shows. A decreasing on the average value of the stator magnetizing inductance as the saturation factor increase can also be noted.

\section{E. Position of the air-gap field}

Let us consider a 2-pole IM in the remaining parts of the paper. Donesco et al. in [17] have reported that the magnetizing inductance depends principally on the stator flux. Such an approximation is better at low slip where the induced rotor flux is low. Therefore, if we admit that the rotating airgap field can be represented with a complex phasor, its spatial position is related to the real and imaginary part of the stator flux-linkage phasor. Thus, having

$\left[\psi_{s}\right]=\left[L_{s}\right]\left[\left[I_{s}\right]+\left[L_{s r}\right] .\left[I_{r}\right]\right.$,

yields

$$
\begin{aligned}
& \bar{\psi}_{s}=\frac{2}{3}\left(\bar{\psi}_{s A}+e^{j \frac{2}{3} \pi} \cdot \bar{\psi}_{s B}+e^{j \frac{4}{3} \pi} \cdot \bar{\psi}_{s C}\right) \\
& \theta_{\psi_{s}}=\operatorname{Arg}\left(\bar{\psi}_{s}\right)=\operatorname{arctg}\left(\frac{\operatorname{Im}\left(\bar{\psi}_{s}\right)}{\operatorname{Re}\left(\bar{\psi}_{s}\right)}\right)
\end{aligned}
$$

$\left[I_{s}\right]$ and $\left[I_{r}\right]$ are $3 \times 1$ and $N_{b} \times 1$ vector element of the motor stator and rotor currents respectively, $\left[L_{s}\right]$ and $\left[L_{s r}\right]$ are the stator inductance matrix and stator-rotor mutual inductance matrix respectively defined as in [15],[16], while $\theta \psi_{s}$ is the instantaneous phase angle of the stator flux-linkage phasor.

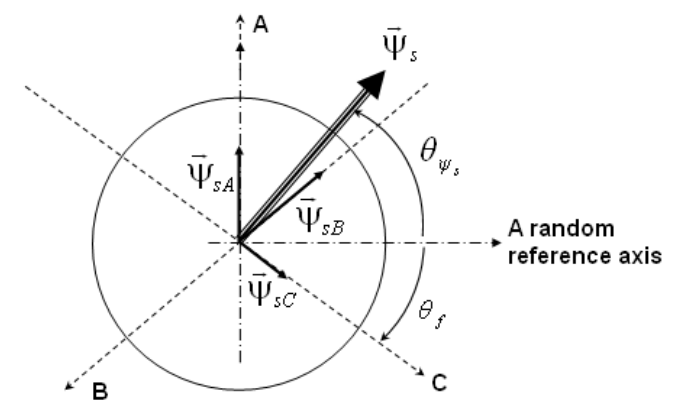

Fig.6. Stator magnetic flux vectors in polar coordinates 
Fig. 6 depicts both angular position of the rotating field $\theta_{f}$ as described in [5] and needed is (11), and $\theta \psi_{s}$ the argument of the corresponding complex phasor. Referring to Fig. 6, a relationship between the magnetic field angles holds

$$
\theta_{f}=\theta_{\psi_{s}}-\frac{\pi}{2}
$$

When considering only the fundamental component of the flux-linkage, it should be noted that equivalent result arises using the argument of the first derivative of the main flux since it is shifted with $\pi / 2$ from the main flux itself [1].

\section{DyNAMIC SIMULATION}

In the system equation of IM based on the MCCM and described in [15], we need to perform time derivative of the inductances. In previews works, the computation of all partial derivative terms with respect to $\theta_{f}$ and $\theta_{r}$ is required [1],[9]. Moreover, a decoupling showing the saturation constants and the field position in separated terms in the inductance expressions is welcome. That is desirable in a dynamic tool able to handle any saturation level for every magnetic field position using the same stored inductances. Hence, from

$$
\left\langle g^{-1} \cdot n_{A}\right\rangle=K_{e} \cdot\left\langle n_{A}\right\rangle+K_{m} \cdot\left\langle n_{A} \cdot \cos \left(\frac{2}{r_{0}} \cdot\left(x-x_{f}\right)\right)\right\rangle,
$$

it is easy to verify that the second term of (33) gives zero. Thus, from (14), (19) and (33), $N_{A}$ depends only from $x$. On the other hand, we can write (11) like

$$
\begin{gathered}
g^{-1}\left(x, x_{f}\right)=K_{e}+K_{\mathrm{m}} \cdot \cos \left(2 \cdot x / r_{0}\right) \cdot \cos \left(2 x_{f} / r_{0}\right) . \\
+K_{\mathrm{m}} \cdot \sin \left(2 \cdot x / r_{0}\right) \cdot \sin \left(2 x_{f} / r_{0}\right)
\end{gathered}
$$

Then, the use of (15) and (34) gives

$$
\begin{aligned}
& L_{A r_{j}}\left(x_{r}, x_{f}\right)=K_{e} \cdot L_{0}\left(x_{r}\right)+ \\
& K_{m} \cdot \cos \left(\frac{2}{r_{0}} \cdot x_{f}\right) \cdot L_{1}\left(x_{r}\right)+K_{m} \cdot \sin \left(\frac{2}{r_{0}} \cdot x_{f}\right) \cdot L_{2}\left(x_{r}\right)
\end{aligned}
$$

with

$$
\begin{aligned}
& L_{0}\left(x_{r}\right)=\mu_{0} \cdot \iint_{S} \underbrace{N_{A}(x)}_{f_{0}(x)} \cdot n_{r_{j}}\left(x_{r}-x, z\right) \cdot d z d x, \\
& L_{1}\left(x_{r}\right)=\mu_{0} \cdot \iint_{S} \underbrace{N_{A}(x) \cdot \cos \left(\frac{2}{r_{0}} \cdot x\right)}_{f_{1}(x)} \cdot n_{r_{j}}\left(x_{r}-x, z\right) \cdot d z d x
\end{aligned}
$$

and

$$
L_{2}\left(x_{r}\right)=\mu_{0} \cdot \iint_{S} \underbrace{N_{A}(x) \cdot \sin \left(\frac{2}{r_{0}} \cdot x\right)}_{f_{2}(x)} \cdot n_{r_{j}}\left(x_{r}-x, z\right) \cdot d z d x .
$$

Next, taking $f_{0,1,2}$ like shown in (36),(37) and (38), allows $L_{0}$, $L_{1}$ and $L_{2}$ to be evaluated independently from $K_{e}, K_{m}$ and $x_{f}$ using the resulting convolution products

$$
L_{i}=\mu_{0} . f_{i} * h \quad \text { with } \quad i=0,1,2 \text {. }
$$

Note that $h$ is the same as in (22) and (24). Now, starting from (35) and the following expression giving the time derivative of the rotor-stator mutual inductance

$$
\frac{d L_{A r_{j}}\left(x_{r}, x_{f}\right)}{d t}=\frac{r_{0} \cdot \partial L_{A r_{j}}\left(x_{r}, x_{f}\right)}{\partial x_{f}} \omega_{s}+\frac{r_{0} \cdot \partial L_{A r_{j}}\left(x_{r}, x_{f}\right)}{\partial x_{r}} \omega_{r},
$$

where $\omega_{s}$ is the line frequency and $\omega_{r}$ is the rotor rotational frequency both in $\mathrm{rad} / \mathrm{s}$. $L_{A r j}$ and its partial derivatives can be easily evaluated inside the iteration loop starting from simple (one dimensional) look-up tables, (35), (40) and the following:

$$
\begin{aligned}
& \frac{\partial L_{A r_{j}}\left(x_{r}, x_{f}\right)}{d x_{f}}= \\
& -2 \cdot \frac{K_{m}}{r_{0}} \sin \left(\frac{2}{r_{0}} \cdot x_{f}\right) \cdot L_{1}\left(x_{r}\right)+2 \cdot \frac{K_{m}}{r_{0}} \cos \left(\frac{2}{r_{0}} \cdot x_{f}\right) \cdot L_{2}\left(x_{r}\right)
\end{aligned}
$$

and

$$
\begin{aligned}
& \frac{\partial L_{A r_{j}}\left(x_{r}, x_{f}\right)}{\partial x_{r}}=K_{e} \cdot \frac{d L_{0}\left(x_{r}\right)}{d x_{r}}+ \\
& K_{m} \cos \left(\frac{2}{r_{0}} \cdot x_{f}\right) \cdot \frac{d L_{1}\left(x_{r}\right)}{d x_{r}}+K_{m} \sin \left(\frac{2}{r_{0}} \cdot x_{f}\right) \cdot \frac{d L_{2}\left(x_{r}\right)}{d x_{r}}
\end{aligned}
$$

The simulation results are done using the same 2-pole 3phase IM in load conditions (the load torque $C_{r}=10$ N.m) fed by idealized supply voltages $(v=1)$. All spectra were drawn in the logarithmic magnitude scale and normalized format. The stator winding is Y-connected (floating neutral). Since the main goal of this work is to describe the new method of inductance calculation, we have just considered an arbitrary saturation level of $K_{s}=1.2$ in order to verify the characteristic frequency components. The current spectra of the unsaturated $\left(K_{s}=1\right)$ and saturated $\left(K_{s}=1.2\right)$ cases are shown in Fig. 7 and Fig. 8 respectively. In Fig. 7 and the top of Fig. 8, it is clear that only RSHs and saturation components associated to nontriplen harmonics are visible since no zero sequence can flow in Y-connected stator windings [5].

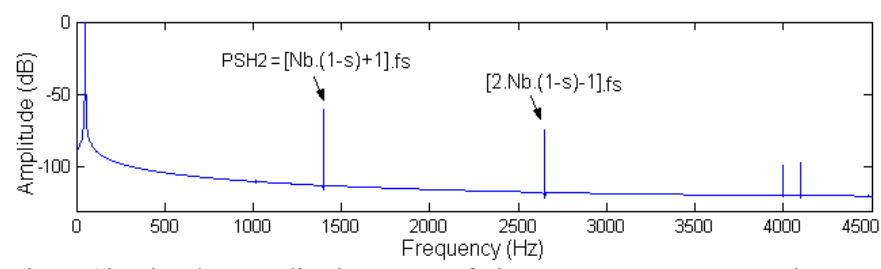

Fig.7. Simulated normalized spectra of the stator current at steady state. Unsaturated IM, s=0.036.

The components predicted by (1) with $n_{s a t}=1$ followed by the subsequent spectral lines corresponding to $n_{\text {sat }}=2$ can be clearly seen in the current spectra of Fig. 8. Similar effects take place besides the line frequency where the $5 \times f_{s}$ harmonic component arises due to saturation followed by the $7 \times f_{s}$ which can be obviously seen as a consequence of the chosen level of saturation. Also, it is shown that in reason of 5\% of supply unbalance, all presumed triplen harmonics show up. As predicted, the flux-linkage contains the predominant third harmonic and this is depicted in Fig. 9 related to the winding with $1 / 3$ pitch, while windings with $2 / 3$ shorted pitch can not generate any triplen component [16]. 

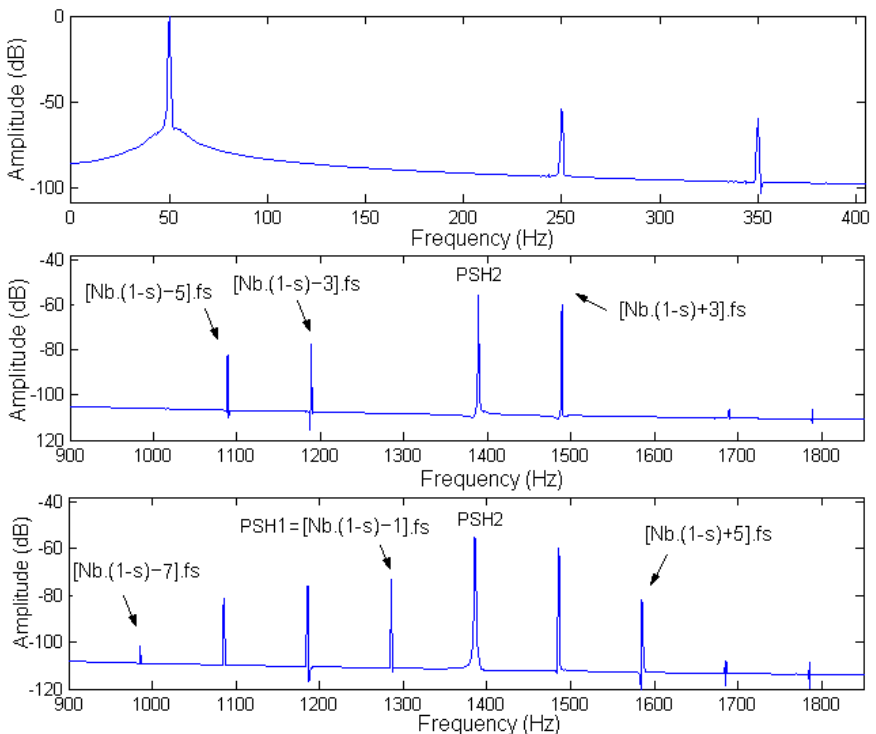

Fig.8. Simulated normalized spectra of the stator current: 1- Saturated IM with $K_{s}=1.2, \mathrm{~s}=0.0441$ and balanced supply (top and middle). $2-K_{s}=1.2$ and some inherent supply unbalance $(5 \%), \mathrm{s}=0.0462$ (bottom).
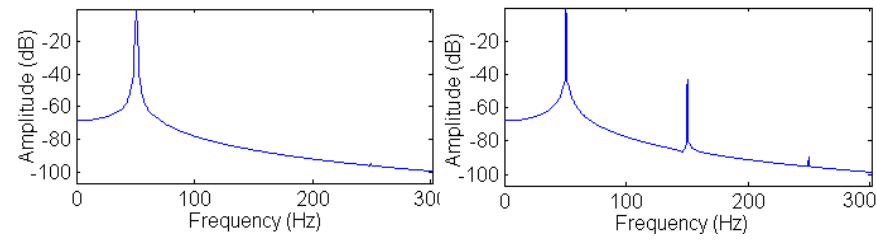

Fig.9. Simulated normalized spectra of the stator flux-linkage. Saturated IM with $K s=1.2$. Winding with $2 / 3$ pitch (left), winding with $1 / 3$ pitch (right).

\section{EXPERIMENTAL VERIFICATION}

The experimental tests are made with the same IM used in simulation. The spectra of Fig. 10 show that even in a healthy state, some frequency components of low amplitudes are perceptible. This is due to the inherent level of rotor asymmetry able to generate component such as $f_{b}=(1-2 s) \cdot f_{s}$ which coincides with a residual mixed eccentricity component $f_{\text {mix ecc }}=|1-2 .(1-s)| \cdot f_{s}$. Moreover, noises introduced by the power supply have a great influence on the stator line current spectra. Even under Y-connection of the stator windings, the $3 . f_{s}$ component appears clearly in the line current spectra as well as all saturation harmonics. As was reported in [1], this may be due to the supply unbalance and the inherent machine constructional asymmetries.
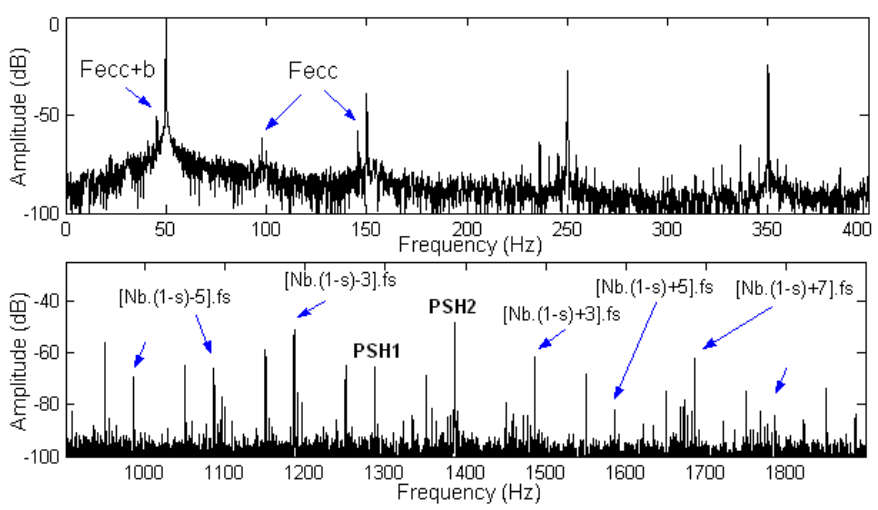

Fig.10. Experimental normalized spectra of the stator current at steady state of the IM with some inherent rotor and supply asymmetries, $\mathrm{s}=0.045$.

\section{CONCLUSION}

The work reported in this paper has successfully applied the theorem of convolution in the time processing optimization of the motor inductances. Such a concept was before intended mainly for time series sampled data analysis. To test the efficiency and applicability of the proposed method, the modeling and simulation of IM in case of rotor and magnetic field position dependency of the inductances (magnetic saturation) were performed.

Last but not least, it must be pointed out that the proposed method of inductance calculation may be extended to incorporate a lot of machine constructional asymmetries and faults as a competitive alternative to the existing solutions.

\section{REFERENCES}

[1] S. Nandi, "A detailed model of induction machines with saturation extendable for fault analysis," IEEE Trans. Indust. Appl., vol.40, no.5, pp. 1302-1309, Sept./Oct. 2005.

[2] A. Stavrou, H.G. Sedding, J. Penman, "Current Monitoring for Detecting Inter-Turn Short Circuits in Induction Motors," IEEE Trans. Energ. Conv., vol. 16, no. 1, pp. 32-37, March 2001.

[3] T.A. Lipo, "Modeling and simulation of induction motors with saturable leakage reactance," IEEE Trans. Indust. Appl., vol. 1A-20, no. 1, pp. 180-189, Jan./Feb. 1984

[4] J.K. Russel , "Steady-state transient analyses of an induction machine with saturation of the magnetizing branch," IEEE Trans. Indust. Appl., vol. 1A-21, no. 1, pp. 226-234, Jan./Feb. 1985.

[5] J.C. Moreira, T.A. Lipo, "Modeling of saturated AC Machines Including Air-Gap Flux Harmonic Components," IEEE Trans. Indust. Appl., vol. 28,no. 2, pp. 343-349, Mar./Apr. 1992.

[6] J.C. Moreira, T.A. Lipo, "A new Method for Rotor Time Constant Tuning in Indirect Field Oriented Control," 1990 IEEE Power Electronics Specialists Conference, San Antonio, pp. 10-15, June 1990.

[7] E. Levis, "Impact of Cross-Saturation on Accuracy of Saturated Induction Machine Models," IEEE Trans. Energ. Conv., vol. 12, no 3, pp. 211-216, Sept. 1997.

[8] D. Bispo, L.M. Neto, J.T. Resende, D.A. Andrade, "A New Strategy for Induction Machines Modeling Taking into Account the Magnetic Saturation,” IEEE Trans. Indust. Appl., vol. 37, no. 6, pp. 1710-1719. Nov. /Dec. 2001

[9] M. Ojaghi, J. Faiz, "Extension to Multiple Coupled Circuit Modeling of Induction Machines to Include Variable Degrees of Saturation Effects," IEEE Trans. Magn., vol. 44, no. 11, pp.4053-4056, Nov. 2008.

[10] "Convolution and deconvolution using the FFT" sample page from Numerical reciptes in fortran 77: The art of scientific computing, Chapter 13-1, pp.531-538.

[11] G. Bossio, C.D. Angelo, J. Solsona, G. García, M.I. Valla, "A 2-D Model of the induction machine: Extension of the modified winding function approach," IEEE Trans. Energ. Conv., vol. 19, no. 1, pp.144$150,2004$.

[12] A. Ghoggal, M. Sahraoui, A. Aboubou, S.E. Zouzou, H. Razik, "An Improved Model of the Induction Machine Dedicated to FaultsDetection - Extension of the Modified Winding Function," In: Proceeding of IEEE ICIT 2005, Hong-Kong, China, 14-17 Dec. 2005.

[13] A. Ghoggal, S.E. Zouzou, H. Razik, M.Sahraoui, A. Khezzar, " An improved model of induction motor for diagnosis purposes - Slot skewing effect and air-gap eccentricity faults," Energ. Conv. Manag. , vol.50, no. 2, pp. 1336-1347, 2009.

[14] P. Schaller, G. Temnov, "Efficient and precise computation of convolutions: Applying FFT To heavy tailed distributions," Computer Methods in Applied Mathematics, vol. 8 (2008), no.2, pp.187-200.

[15] X. Luo, Y. Liao, H.A. Toliyat, A. El-Antably and T.A. Lipo, "Multiple coupled circuit modeling of induction machines," IEEE Trans. Indust. Appl., vol. 31, no. 2, pp. 311-318, Mar./Apr. 1995.

[16] D. Gaïtan, "Modélisation et diagnostic de la machine asynchrone en présence de défaillance," Phd dissertation, Université Henri Poincaré, Nancy-I, France, Oct. 2004

[17] V. Donesco, A. Charette, Z. Yao, V. Rajagoplan, "Modeling and Simulation of Saturated Induction Motors in Phase Quantities," IEEE Trans. Energ. Conv., vol. 14, no. 3, pp. 386-393, Sept. 1999. 